\title{
Thermo-mechanical analysis of the Wendelstein 7-X divertor
}

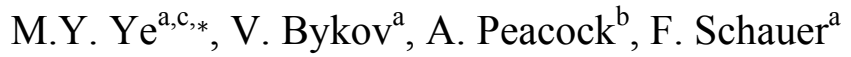 \\ ${ }^{a}$ Max-Planck-Institut Für Plasmaphysik Teilinstitut Greifswald, Wendelsteinstraße 1, D-17491 Greifswald, \\ Germany \\ ${ }^{b}$ Max-Planck-Institut Für Plasmaphysik, Boltzmannstraße 2, D-85748, Garching bei München, Germany \\ ${ }^{c}$ Institute of Plasma Physics, Chinese Academy of Sciences, 230031 Hefei, PR ChinaMax-Planck-Institute für \\ Plasmaphysik
}


Abstract- The stellarator Wendelstein 7-X (W7-X) has a divertor consisting of 10 units installed inside the plasma vessel (PV). It was decided not to install the long pulse high-heat flux (HHF) divertor targets at the first two years stage of W7-X operation and to start with an adiabatically cooled test divertor unit (TDU) and shorter plasma pulses operation. This allows to accumulate operation experience with much simpler components, and as a result to adjust accurately the actively cooled HHF divertor which replaces the TDU for the stationary operation. Finite element (FE) analyses have been performed for better understanding of thermo-mechanical problems of divertor targets, and to guide the design of the TDU and HHF divertors.

This paper presents the detailed results of the temperature response, the deformation and thermal stress of the divertor components.

Keywords: W7-X stellarator, High heat load, Divertor, Thermo-mechanical finite element analysis 


\section{Introduction}

$\mathrm{W} 7-\mathrm{X}$ (major radius $\mathrm{R}=5.5 \mathrm{~m}$, minor radius $\mathrm{a}=0.55 \mathrm{~m}$, five periods) is designed for stationary operation $(30 \mathrm{~min})$ at $\mathrm{Bo} \approx 3 \mathrm{~T}$ with continuous wave heating by ECRH with up to 10MW power, and additional heating by NBI and ICRH with power up to $14 \mathrm{MW}$ for $10 \mathrm{~s}$. W7-X is now under construction at Max-Planck Institute for Plasma Physics in Greifswald. The goal of the experiment is to demonstrate the suitability of the advanced stellarator concept as a desirable alternative to the tokamak for a future fusion reactor $[1,2]$.

W7-X has a divertor consisting of 10 units installed inside the PV along the helical edge of the plasma contour to control the energy and particle flow at the plasma boundary under steady state operation. For long-pulse plasma operation of W7-X, the actively water cooled HHF target plates are designed to withstand thermal loads up to $10 \mathrm{MW} / \mathrm{m}^{2}[3,4]$. However, it has been decided for the first stage of W7-X operation to start with TDU for shorter plasma pulse operation. Afterward, the TDU will be replaced with the actively cooled HHF divertor for stationary operation. In order to accumulate operation experience during TDU phase as relevant as possible, the geometry features of the TDU and the HHF are largely similar [5]. The TDU, like the HHF divertor, consists of four distinct areas, see Fig. 1. These are the horizontal target, the vertical target, the high Iota tail and the low heat-flux region between the high Iota tail and the horizontal target [1].

One of the most serious challenges for the design of plasma facing components is the thermo-mechanical problem [6,7]. In order to develop and confirm the design of the TDU and the HHF divertors, FE calculations with ANSYS $^{\circledR}$ code have been performed to resolve the following thermo-mechanical issues: (a) Pulse length of plasma operation and temperatures of the in-vessel components for the TDU phase, (b) Temperature distribution and maximum 
temperature of the target elements, (c) Bowing and overall deflection of the target elements, cooling pipes, and so on, (d) Thermal stresses in each component.

\section{TDU}

\subsection{Thermal analysis of TDU}

During the first pulse operation stage ofW7-Xexperiments, passive cooling is to be used not only for TDU but also for some other in-vessel components. For high power operation up to 8 $10 \mathrm{MW}$, the un-cooled divertor target is rapidly heated up and becomes a heat source for other in-vessel components due to thermal radiation. Therefore it is very important to analyse the thermal behaviour of the passive target and other in-vessel components since the allowable temperature limits strictly define the duration of the pulse, the dwell time and the number of sequential cycles. The FE thermal analyses have been carried out with simplified 2D FE model (see Fig. 2) where the TDU target is a simplified flat graphite tile $(30 \mathrm{~mm}$ thickness, $400 \mathrm{~mm}$ length). The shield between the target and the stainless steel (SS) thin pipes protects the pipes from direct radiation from the backside of the target. The baffles are made of fine grained graphite, while the lines and PV are made of SS.

The maximum energy of $50 \mathrm{MJ}$ with a power density of $8 \mathrm{MW} / \mathrm{m}^{2}$ is applied on the target central area of $10 \mathrm{~cm}$ (width of strike line). The actively cooled PV is simulated by fixed temperature of $20^{\circ} \mathrm{C}$ in the cooling channels, while other components are kept passive.

The calculation of the heat transfer by thermal radiation was performed for 50 cycles with the heat load applied for $6.25 \mathrm{~s}$ and a dwell time of $10 \mathrm{~min}$ between cycles. The temperature of all components approaches an equilibrium state after 50 cycles. The maximum temperatures of invessel components after 10 and 50 cycles are listed in Table 1.

The maximum temperature of the target front reaches $1962{ }^{\circ} \mathrm{C}$ and $1913{ }^{\circ} \mathrm{C}$ after 50 and 10 cycles, respectively, which are both beyond the limit of about $1800{ }^{\circ} \mathrm{C}$ (sublimation 
temperature of the graphite). The temperature of the baffles is less than the mentioned above allowable value. Also the temperature of the copper chromium zirconium $(\mathrm{CuCrZr})$ heat sink at the baffle backside stays below the allowable $450{ }^{\circ} \mathrm{C}$. The temperature of $231{ }^{\circ} \mathrm{C}$ at the liner-2 after 10 cycles is slightly higher than the allowable temperature of $200{ }^{\circ} \mathrm{C}$. In addition, the shield behind the target is heated up to $400{ }^{\circ} \mathrm{C}$ due to high radiation heat from the target backside $\left(788{ }^{\circ} \mathrm{C}\right)$. Therefore an appropriate material should be used for the shield. Further analysis for 10 cycles has been performed for longer pulse operations (12.5 s and $25 \mathrm{~s})$ with the same input energy onto target and smaller heat flux density of $4 \mathrm{MW} / \mathrm{m}^{2}$ and $2 \mathrm{MW} / \mathrm{m}^{2}$, respectively. The calculated results show that the peak temperature reached at the target decreases down to $1461{ }^{\circ} \mathrm{C}$ and $1153{ }^{\circ} \mathrm{C}$, respectively, but the temperatures of other components do not change due to the same input energy.

In order to avoid that both the surface temperatures of the target exceed the allowable $1800^{\circ} \mathrm{C}$ and the component temperatures exceed the specified limits, duty cycles of operation should be longer than $10 \mathrm{~min}$, the pulse length should be limited to less than $10 \mathrm{~s}$ for full power operation, and restrictions on the number of sequential cycles have to be taken into account.

\subsection{The thermal stresses and deformation of TDU}

The TDU design is based on fine grained graphite instead of carbon-carbon fibre (CFC), bonded to water cooled copper. Each target module comprises 7 or 8 tiles which are mounted onto a SS module frame by springs (see Fig. 3). The graphite tiles are $30 \mathrm{~mm}$ thick, $50 \mathrm{~mm}$ wide and 250-600 mm long, depending on location. They are castellated with slots $6 \mathrm{~mm}$ deep and $1 \mathrm{~mm}$ wide at $25 \mathrm{~mm}$ intervals along their length. Each spring is fastened at one end to the graphite tile, via a titanium zirconium molybdenum (TZM) pin and a screw, and at the other end to the frame. The springs and screws are made of Inconel 625 which has good mechanical properties and low conductivity at high temperature. Such material choice 
minimises the heat transfer to the module frame and allows cooling of the tiles by thermal radiation loss. In order to avoid large deformation of the central area of the tiles an additional TZM pin is used inside the tile and connected to a central support frame as shown in Fig. 3b. The pin allows the tile to rotate freely around the pin. Thermo-mechanical analysis of one target module has been carried out using a 3D FE model. The following heat load and the boundary conditions are used: (a) The temperature field calculated with a heat load of $8 \mathrm{MW} / \mathrm{m}^{2}$ is applied for $6.5 \mathrm{~s}$ on the central area or on the edge area with a width of $10 \mathrm{cmis}$ used for the static mechanical analysis. (b) Each spring is fastened at one end to the graphite tile, and at the other end to the support frame. Positions A and B of the support frame (see Fig. 3a) are fully fixed, while $\mathrm{C}$ and $\mathrm{D}$ allow in plane sliding. (c) The tiles are restrained from moving upwards by the TZM pin, and are allowed to rotate a small angle. (d) Radiation from hot top surface of the tiles is considered.

Fig. 4a shows the temperature distribution of one target module at $6.5 \mathrm{~s}$. The top surface temperature variation over the central area of the tile (width $\approx 10 \mathrm{~cm}$ ) is about $1400{ }^{\circ} \mathrm{C}<\mathrm{T}<$ $1780{ }^{\circ} \mathrm{C}$. The temperature at the end of tile is still kept at low temperature. As a result a maximum total deflection of about $0.6 \mathrm{~mm}$ is observed at the edge of the tile, at the centre of the heat loaded area it is about $0.4 \mathrm{~mm}$. Fig. $4 \mathrm{~b}$ shows the deflection in vertical (Z-axis) direction. The positive and negative values signify the movements downwards and upwards, respectively. The maximum movement at the centre of heat loaded area is about $0.3 \mathrm{~mm}$ upwards, at the edge of the tile it is about $0.5 \mathrm{~mm}$ downwards. The Von Mises stress in graphite tile is not beyond $40 \mathrm{MPa}$ and stresses in TZM pins are below $100 \mathrm{MPa}$. A maximum stress of about $277 \mathrm{MPa}$ is observed in the Inconel spring. The value does not exceed the maximum allowable limit $(3 * \mathrm{Sm})$ of $957 \mathrm{MPa}$ at room temperature for the combination of primary and secondary stresses. Similar analysis has been performed for the case of heat load 
applied to the edge area of the tiles above the spring support region. The maximum temperature of the surfaces of the tiles arrives at $1775^{\circ} \mathrm{C}$ at $6.5 \mathrm{~s}$. The temperature of the Inconel spring is about $300{ }^{\circ} \mathrm{C}$. The maximum movement at the edge of the tile is about 0.9 $\mathrm{mm}$ downwards. The stress in graphite tile is also not beyond $40 \mathrm{MPa}$ and the maximum stress of about $251 \mathrm{MPa}$ observed in the Inconel spring at about $300^{\circ} \mathrm{C}$ is below the allowable stress limit of $820 \mathrm{MPa}$.

\section{HHF}

The HHF divertor targets are made of 3D reinforced CFC NB31 as plasma facing material which is bonded via an active metal casting (AMC) copper interlayer to the water cooled $\mathrm{CuCrZr}$ structure [3]. The NB31 presents better mechanical properties to guarantee the reliability of the joint to the heat sink. The $\mathrm{CuCrZr}$ elements are grouped into modules (between 8 and 12 elements per module) in which the elements are supported on a SS module frame. Special pipes connect the elements to water manifolds mounted on the back of the module frame. Depending on the location within the machine, 3 or 4modules are mounted together to form the divertor as shown in Fig. 1. The thicknesses of $\mathrm{CFC}, \mathrm{Cu}$ interlayer and $\mathrm{CuCrZr}$ are $8 \mathrm{~mm}, 3 \mathrm{~mm}$ and $19 \mathrm{~mm}$, respectively. The width of the target element is about $55 \mathrm{~mm}$.

Each target element of type 3 (for horizontal target) or type 5 (for vertical target) is mounted on the support frame by two supports as shown in Fig. 5b. The support point near the water inlet fully fixes the target element against the frame. The second point fixes the target element just against movements perpendicularly to the frame for allowing thermal expansion. For long target elements of type 1 (for horizontal target) three support points are considered as shown in Fig. 5a. But the third support point is not considered in calculations because it is not mounted on the target modules to avoid mechanical stresses, and just connect the target elements 
together. The water cooling channels inside the target elements are shown in Fig. 5c.

Thermo-mechanical analyses have been performed with 3D FE models of the target elements without the target frame. The aim was to estimate temperature levels, deflections and stresses for the elements, the pipe connectors and the fixings. Orthotropic heat conductivity and thermal expansion coefficient for 3D CFC were used. The following heat loads and boundary conditions were taken: (a) $10 \mathrm{MW} / \mathrm{m}^{2}$ over a width of $10 \mathrm{~cm}$ applied on the central area of the element as load case 1 (LC1) or on the area above the water connection region as load case 2 (LC2) for the static mechanical analysis. (b) Support 1 is fully fixed and support 2 allows sliding in horizontal direction. The option with allowed rotation in this point is also investigated as a measure to avoid high stresses in fixings. (c) The heat from wall to cooling water is defined by $\mathrm{q}=\mathrm{h}$ (Twall - Twater) with the wall heat transfer coefficient $\mathrm{h}$ as a function of temperature. (d) Radiation cooling from hot surface of the CFC.

Fig. 6 shows the results for type 1 HHF element in case of the heat load applied to the central area of the element between support 1 and 2. The maximum temperatures of $\mathrm{CFC}$ tile, $\mathrm{Cu}$ layer and $\mathrm{CuCrZr}$ heat sink are $885{ }^{\circ} \mathrm{C}, 423{ }^{\circ} \mathrm{C}$ and $266^{\circ} \mathrm{C}$, respectively, which are acceptable for the components. The profiles of the surface temperature of three components and vertical deflection of the element along the path from A to B (see Fig. 5a) are presented in Fig. 6 a.

The positive value and negative value signify the movement downwards and upwards, respectively. The maximum movement at the centre of heat load application area is about $0.8 \mathrm{~mm}$ upwards. The maximum movement at the end of the tile is about $2.0 \mathrm{~mm}$ downwards where the support is not constrained. The deflection of the pipe connector is about $0.6 \mathrm{~mm}$. The profiles of the stresses of three components along the path from A to B are plotted in Fig. 6b. The Von Mises stress is not beyond $100 \mathrm{MPa}$ in CFC tile and is below $150 \mathrm{MPa}$ in $\mathrm{CuCrZr}$ heat sink. But the stresses reach $550 \mathrm{MPa}$ in $\mathrm{Cu}$ layer and $530 \mathrm{MPa}$ at the support position. 
However, the $\mathrm{Cu}$ stresses are not real since elastic material properties were assumed in the analysis. The $\mathrm{Cu}$ layer is intended to yield plastically, and its proper function was tested extensively [8]. Similar calculations performed for type 3 and type 5 elements with different heat load areas show that the temperature of the $\mathrm{CFC}$ is not beyond $1000{ }^{\circ} \mathrm{C}$ for all cases, the deflection is still below $2 \mathrm{~mm}$. However, the stress levels in the support 1 region for type 5 of $788 \mathrm{MPa}$ and $894 \mathrm{MPa}$ for LC1 and LC2, respectively, are clearly above the limits. The high stresses result from the fully fixed boundary condition. To avoid these high stresses, the variant with rotation allowed in both supports was considered. The results show considerable reduction of the stresses in support 1 for LC2 from $894 \mathrm{MPa}$ to $190 \mathrm{MPa}$. The change of boundary conditions does not result in an enhanced movement of the element.

\section{Summary}

FE thermo-mechanical analyses have been carried out for the W7-X divertors. The design of the TDU without active cooling has been verified by FE analyses with the main conclusion that the passively cooled TDU meets the main requirements for the first stage pulse operation of W7-X. However, some limitations summarised in Section 2.1 are to be taken into account. For the HHF divertor the FE calculations indicate that the temperatures of all components of the target element remain within an acceptable range for the heat flux of $10 \mathrm{MW} / \mathrm{m}^{2}$ under stationary operation. To avoid high stresses, rotation in the supports has to be allowed. However in order to get correct deformation and stresses the exact geometry should be taken into account. Further FE analyses are to be performed for the design of the HHF divertor with a FE model which includes a more realistic support structure and will be compared with experimental tests in Gladis facility [8]. 


\section{References}

[1] J. Kißlinger, C. Beidler, E. Harmeyer, F. Rau, H. Renner, H. Wobig, Proceedings of 21st European Conference on Controlled Fusion and Plasma Heating, Montpellier, vol. 18C Part I, European Physical Society, 1994.

[2] H. Renner, J. Boscary, V. Erckmann, H. Greuner, H. Grote, J. Sapper, et al., Nucl. Fusion $40(2000) 1083$.

[3] H. Greuner, B. Böswirth, J. Boscary, G. Hofmann, B. Mendelevitch, H. Renner, et al., Fusion Eng. Des. 66-68 (2003) 447.

[4] J. Boscary, H. Greuner, T. Friedrich, H. Traxler, B. Mendelevitch, B. Böswirth, et al., Fusion Eng. Des. 84 (2009) 497.

[5] A. Peacock, H. Greuner, F. Hurd, J. Kißlinger, R. König, B. Mendelevitch, et al., Fusion Eng. Des. 84 (2009) 1475.

[6] M.Y. Ye, A. Werner, M. Hirsch, H. Thomsen, A. Weller, R. König, AIP Conf. Proc. 993 (211) (2008) 211.

[7] M.Y. Ye, M. Hirsch, R. König, M. Laux, H. Thomsen, A. Weller, et al., Fusion Eng. Des. $84(2009) 2002$.

[8] H. Greuner, U. v. Toussaint, B. Böswirth, J. Boscary, H. Maier, A. Peacock, et al., FusionEng.Des. 86 (2011) 1685. 
Figures

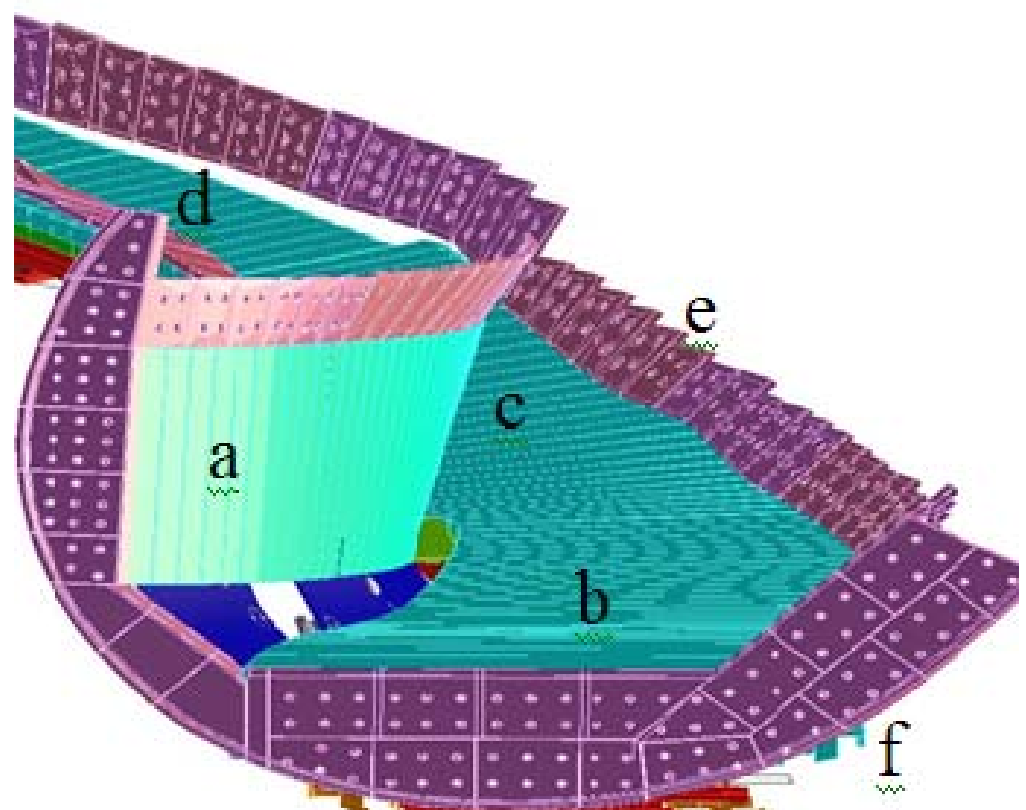

Fig. 1. Front surfaces of the TDU: (a) Vertical target, (b) horizontal target, (c) low heat flux area, (d) high Iota tail, surrounded by (e) baffle and (f) toroidal closure.AD view of W7-X. 


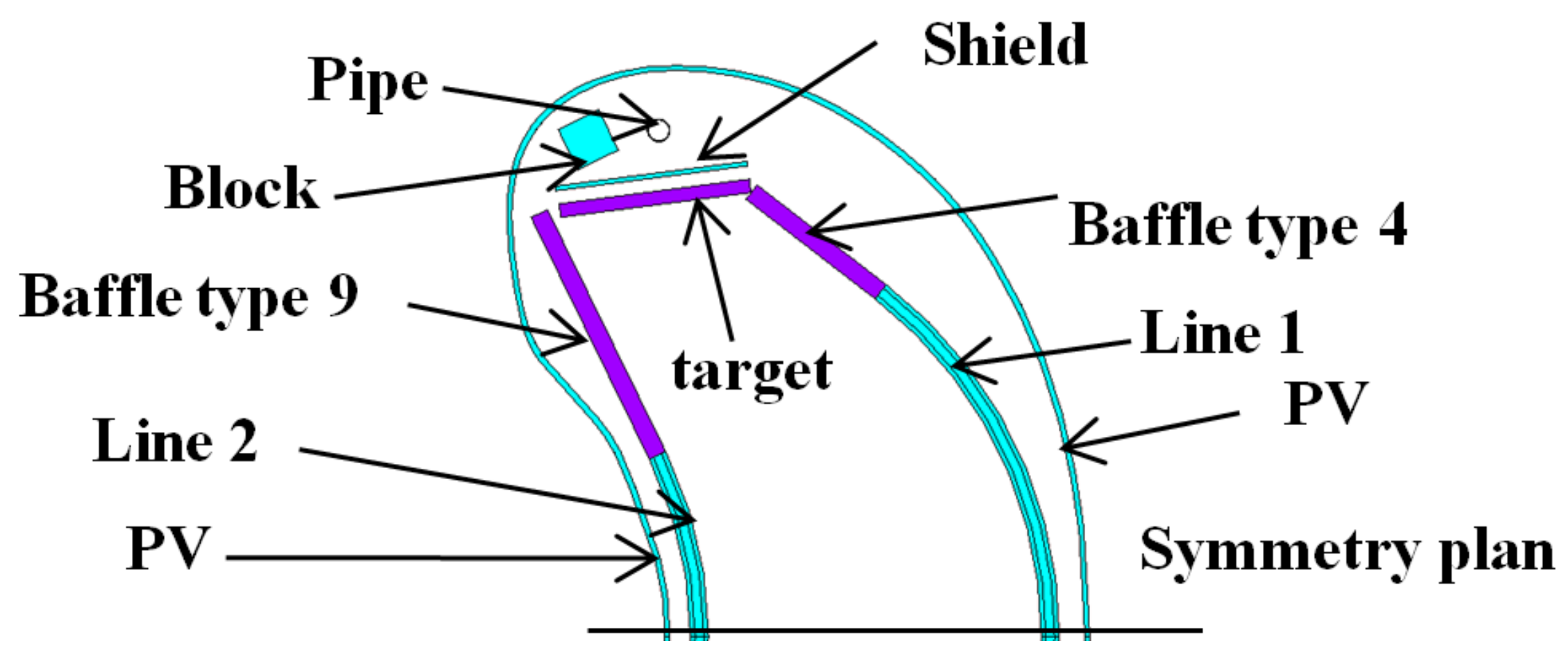

Fig. 2. Simplified 2D model of bean-shaped cross section of W7-X plasma vessel. 

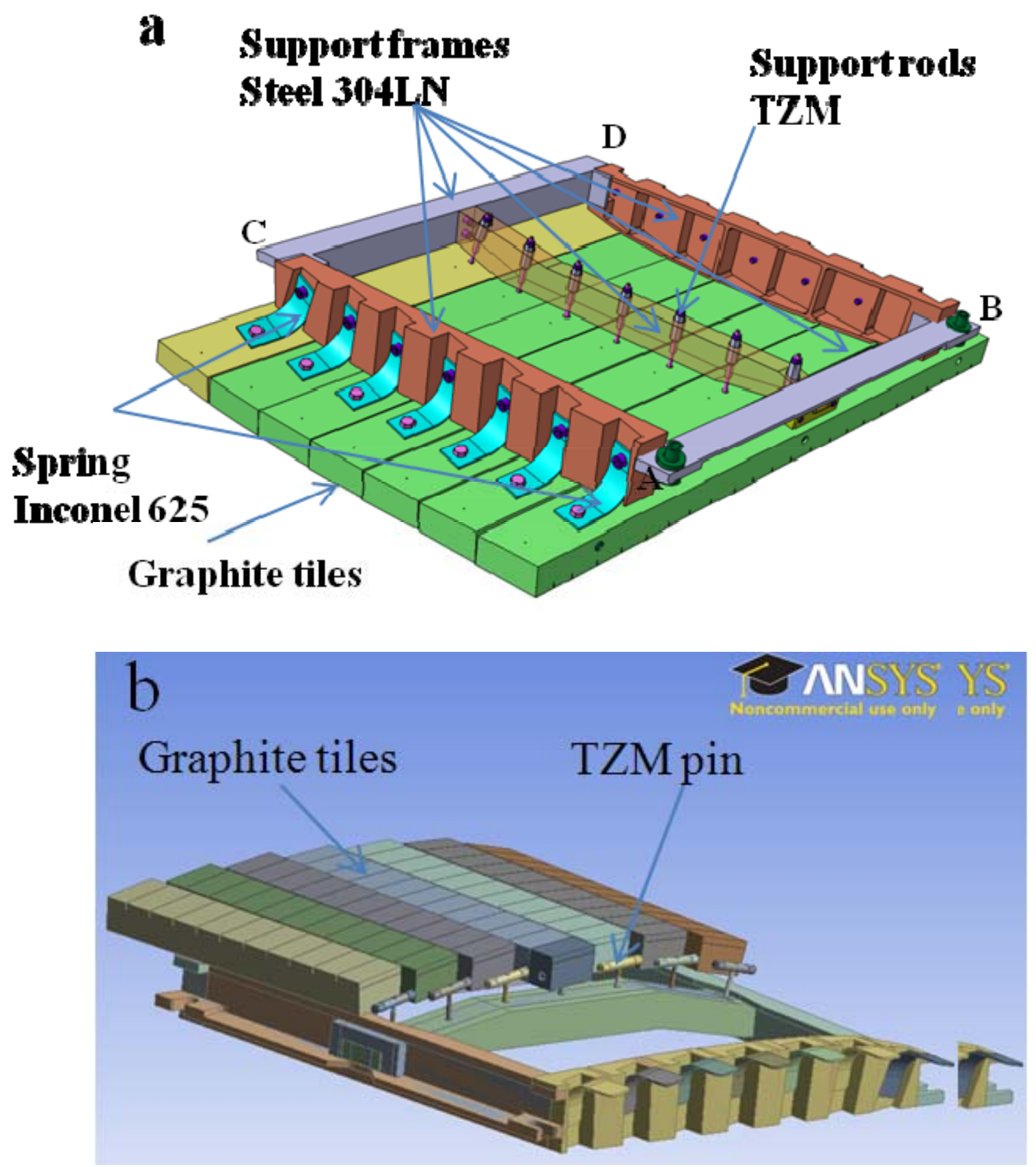

Fig. 3. TDU module (a) backside view with focus on attachment features and (b) view from plasma side with indication of TZM pins (part of tiles are removed). 

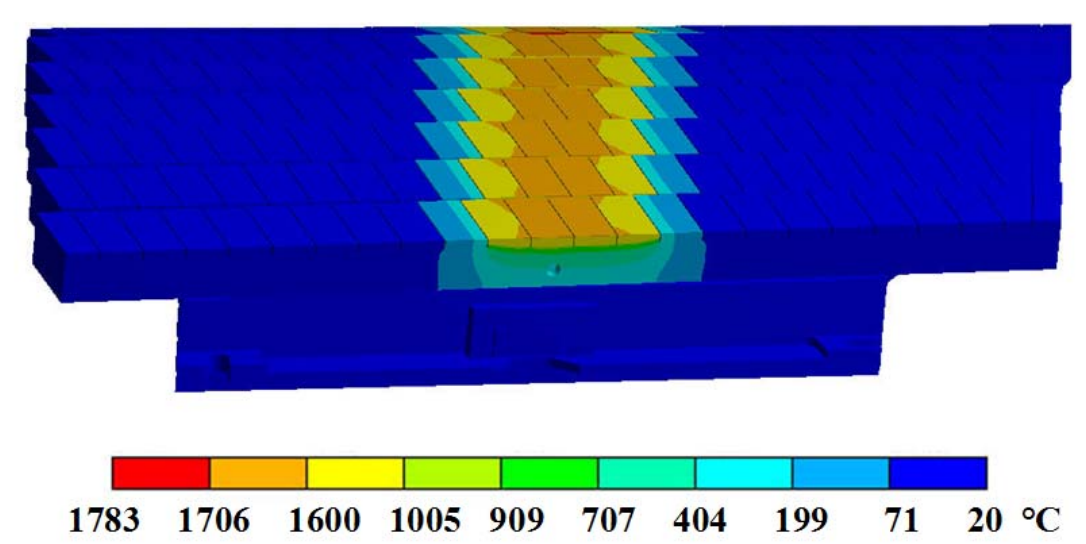

b
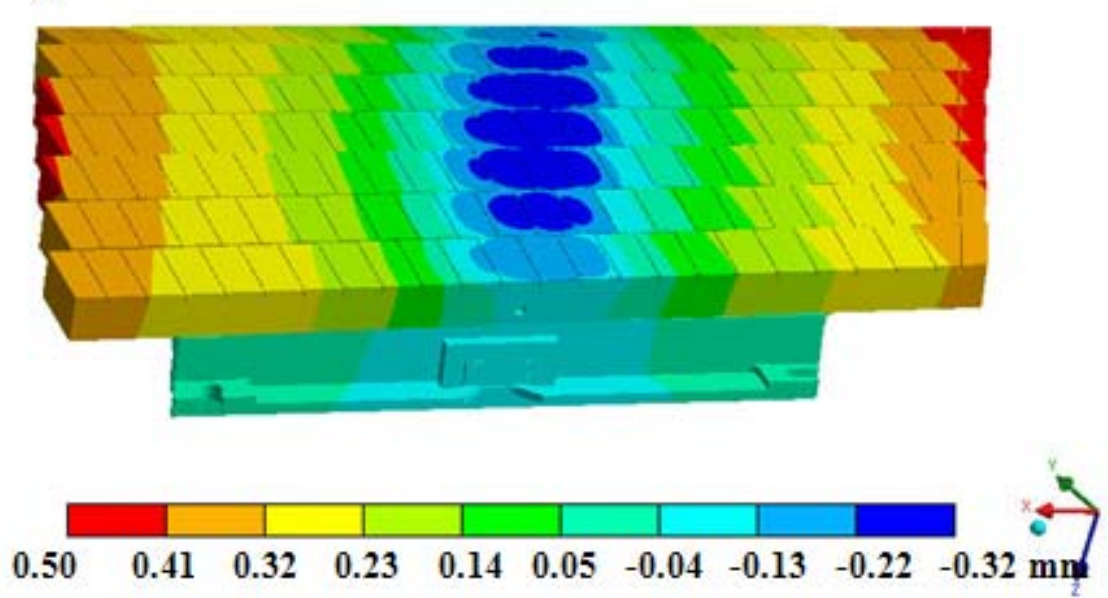

Fig. 4. (a) Temperature distribution after application of $8 \mathrm{MW} / \mathrm{m} 2$ on central area of tiles for $6.5 \mathrm{~s}$. (b) Deflections in vertical direction (mm) of the TDU module. 
a

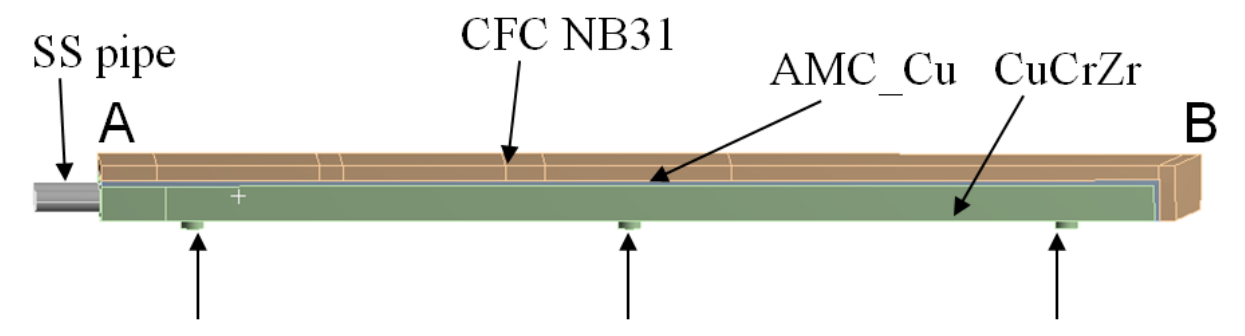

Support_1 Fixed Support_2 Sliding Support_3 Free

b

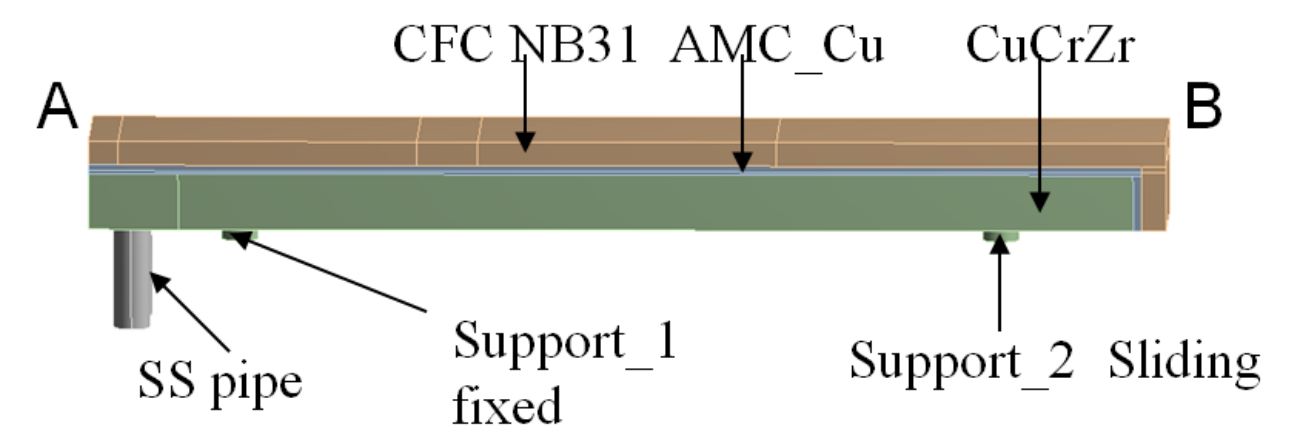

c

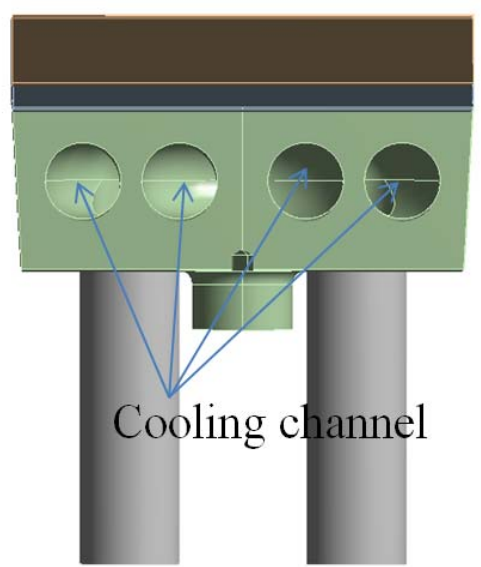

Fig. 5. Geometry of target element: (a) type 1, (b) type 5 and (c) cross section of type 5 with water cooling channels. 


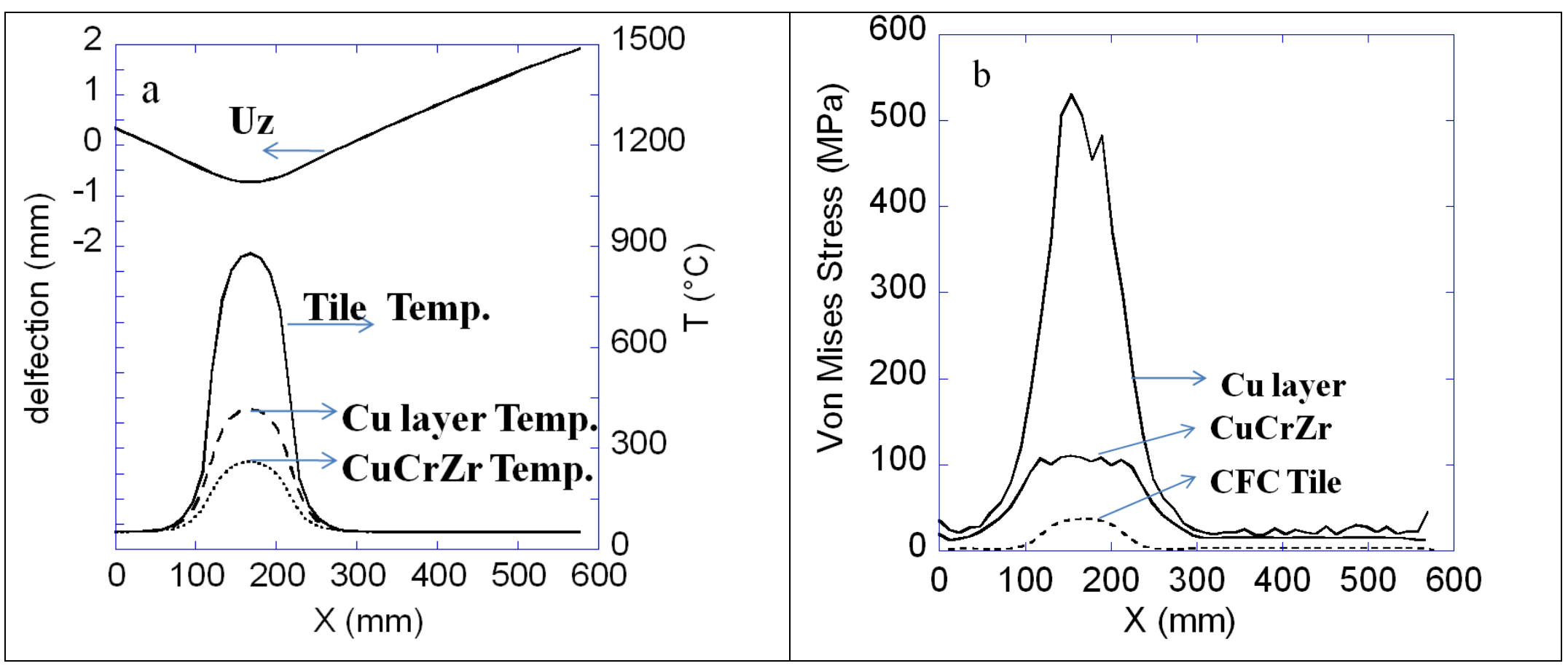

Fig. 6. Detail Profiles along path from A to B (see Fig. 5a) (a) surface temperature for three components and vertical deflection of HHF element. (b) Von Mises Stress. 
Table 1: Maximum temperature of in-vessel components

\begin{tabular}{lll}
\hline Case: $8 \mathrm{MW} / \mathrm{m}^{2}$, & $\mathrm{T}_{\max }\left({ }^{\circ} \mathrm{C}\right)$ after & $\mathrm{T}_{\max }\left({ }^{\circ} \mathrm{C}\right)$ after \\
$6.25 \mathrm{~s}$ & 10 cycles & 50 cycles \\
\hline Target front side & 1913 & 1962 \\
Target back side & 788 & 832 \\
Baffle-4 & 208 & 352 \\
Baffle-9 & 247 & 383 \\
Liner-1 & 204 & 333 \\
Liner-2 & 231 & 368 \\
Shield & 400 & 460 \\
Pipe & 196 & 280 \\
Block & 48 & 220 \\
PV & 30 & 39 \\
\hline
\end{tabular}

